\title{
An instrumental partial reinforcement effect in the absence of any overt instrumental acquisition training*
}

\author{
E. J. CAPALDI, ELIZABETH D. CAPALDI, and KENNETH KASSOVER \\ Purdue University, West Lafayette, Ind. 47907
}

Rats were placed directly over a food cup or received ordinary runway trials under either partial or consistent food reward, no other acquisition training having been given. Also included was a group that was nonrewarded on all running trials. A gradient occurred in extinction such that type of acquisition training (placed vs run) exercised less influence over performance and schedule of reward (partial vs continuous) exercised more influence over performance both as extinction training progressed and as the goal section was approached. The results suggest that rats make small terminal instrumental reactions on placement trials, reactions which, if strongly conditioned, can support a partial reinforcement effect in the full instrumental reaction, particularly in the goal area.

The present experiment attempted to determine whether or not placing rats directly over the food cup in an alley (DPs) without explicit opportunity for instrumental responding and in the absence of any other kind of instrumental training would produce a partial reinforcement effect (PRE). In the present experiment no instrumental training whatsoever accompanied the DP trials. Training was thus more severe than in previous DP studies (Trapold \& Doren, 1966; Trapold \& Holden, 1966; Wilton, 1967) in which DPs were administered in the context of consistently rewarded instrumental trials. Thus, for the DP groups the first explicit instrumental trial was a nonreinforced extinction trial.

\section{SUBJECTS}

The Ss, 70 naive male rats about 90 days old on arrival at the laboratory, were purchased from Holtzman Co., Madison, Wisconsin.

\section{APPARATUS}

The apparatus was a straight alley, 82 in. long, 4 in. wide, and enclosed by 9 -in.-high sides, covered with hinged $1 / 2$-in. hardware cloth. It was constructed of wood and painted a mid-gray. It had three basic sections: a 14-in. start section, a 52-in. run section, and a 16-in. goal section. On running trials the $S$ was placed at the rear of a 10 -in. start treadle, starting a $.01-\mathrm{sec}$ clock. This clock stopped and a second started when the $S$ broke an infrared beam 4 in. from the treadle's tip (start time). Interrupting the second beam, 52 in. from the first, stopped the second clock (run time) and started a third clock. Twelve inches from the second beam and 2 in. from the front edge of a brass $2 \times 4 \frac{1}{4} \times 1 \frac{1}{2}$ in. food cup, covered by a

*This investigation was supported in part by National Institute of Child Health and Human Development Research Grant HD04379 to the first author. tightly fitting, automatically controlled, sliding metal lid operated by an electric motor was a third infrared beam. Interrupting it stopped the third and last clock (goal time) and opened the lid covering the food cup. When $S$ broke the third beam, a brass guillotine door, 12 in. from the alley's distal end, was lowered manually, thereby confining $S$ to the goal area.

\section{PROCEDURE}

The Ss were run in seven replications of $10 \mathrm{Ss}$ each. All Ss received ad lib food and water for 6 days after arrival in the laboratory. On the seventh day after arrival, the $S s$ in the first replication were placed on a $12-\mathrm{g} /$ day deprivation schedule that continued throughout the experiment, water being given ad lib. On the eighth day after arrival, the $S s$ in the second replication were placed on deprivation, etc. The Ss in a given replication remained on ad lib food and water until their deprivation began. On Days 10-12 of deprivation each $\mathbf{S}$ was handled for $10 \mathrm{~min}$ outside the home cage and received 12 .045 -g Noyes pellets in the home cage. This amount was subtracted from their daily ration, as was the amount of reinforcement received in acquisition each day. On Day 12 of deprivation the $10 \mathrm{Ss}$ in a replication were distributed equally among five groups. Each replication was run in two squads of five, each composed of one $S$ from each group. There were two Es, each of whom ran one squad of each replication. The five groups differed in type of acquisition training (placed or run) and schedule of reward (partial reward, consistent reward, or consistent nonreward). The five groups were: PP-placed partial, PC-placed consistent, $\mathrm{PN}$-placed nonreward, RP-run partial, and $\mathrm{RC}-$ run consistent. There were 8 days of acquisition (five trials/day), during which the placed groups received only placements and the run groups received only running trials. On placed trials the $S$ was placed directly into the goalbox over the food cup. The $S$ was placed such that S's body and E's hand broke the last photobeam (thus opening the food cup lid) and S's mouth and head were directly over the food. The partial groups (PP and RP) received $50 \%$ partial reward, the sequence of rewards ( $R, 12$ pellets) and nonrewards (N) being RNNNR on odd days and NRNNR on even days. Groups PC and RC were rewarded on every trial (12 pellets), while Group PN was nonrewarded on every trial. On nonrewarded trials $\mathrm{Ss}$ were removed from the goalbox after $30 \mathrm{sec}$, while on rewarded trials they were removed immediately after consuming all the reinforcement. In both acquisition and extinction, Ss were run in rotation within a squad, resulting in a minimum intertrial interval of $4 \mathrm{~min}$. Squads were run in the same order each day, but the order of running within a squad was changed daily so that the $S$ who was first on Day 1 was last on Day 2 and all other Ss moved up one place in the running order. The $S$ s in a squad were fed their daily ration $10 \mathrm{~min}$ after the last $S$ in the squad completed its last trial. There were 15 extinction trials on the day following acquisition. In extinction, running trials were given as described above, except that the guillotine door was not lowered and $S$ was removed from the goalbox as soon as possible (about $5 \mathrm{sec}$ ). In extinction if $S$ failed to traverse the runway in less than $180 \mathrm{sec}$, it was forced gently into the goalbox. The maximum time recorded for any one section was $60 \mathrm{sec}$. During the course of the experiment, two Ss from Group PN died and their data were discarded.

\section{RESULTS}

All analyses were for unequal ns and were applied to speeds $(1 / \mathrm{sec})$ in each alley section. On the last day of acquisition the difference between Groups RP and RC was not significant in any alley section (all Fs $<1$ ). Figure 1 shows speed of running in each alley section for each group on the extinction trials in blocks of five trials. As may be seen in Fig. 1, the two running groups, RP and RC, show the typical PRE in all alley sections. The placed groups tended to speed up over blocks of nonrewarded trials, due perhaps to the diminution of fear, the decline of exploratory tendencies, etc. The amount of speed increase over blocks was greater for Group PP than for Group PC, and these increases over blocks were greater in Group PP as the goal section was approached.

A 2 by 2 factorial analysis with Group PN appended, followed by a Duncan's range test, was performed in each 

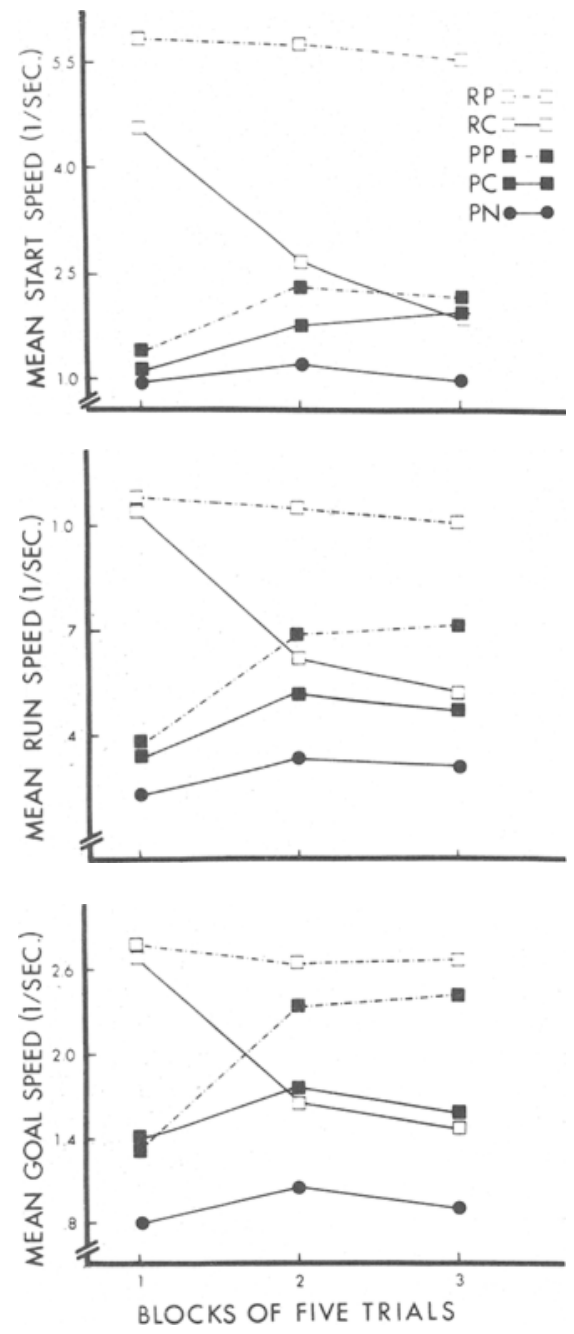

Fig. 1. Speed of running in each alley section for each group on the nonrewarded extinction trials in blocks of five trials.

alley section on each block of five trials. In each of the nine overall analyses, the differences between groups were significant at the .005 level or better, as were the differences between Group PN and the remaining groups combined. The analyses substantiated the two opposed trends which may be seen in Fig. 1. On the one hand, the influence on performance of type of acquisition training, placed vs run, declined both as extinction training progressed and as the goal section was approached. Thus, in the start section the run groups were significantly faster than the placed groups even by the third block of trials $(\mathrm{F}=19.33, \mathrm{df}=1 / 63, \mathrm{p}<.001)$, while in the goal section type of acquisition training was significant only on the first block of trials $(F=69.93$, $\mathrm{df}=1 / 63, \mathrm{p}<.001$ ), not being significant on the second or third block of trials $(F s<1)$. On the other hand, the influence on performance of schedule of reward, partial vs consistent, increased both as extinction training progressed and as the goal section was approached. On the first block of trials, differences due to reward schedule were significant only in the start section $(F=5.62, \mathrm{df}=1 / 63, \mathrm{p}<.05)$. By the third block of trials, reward schedule differences were highly significant in all alley sections (start, $F=27.13$; run, $\mathrm{F}=45.18 ;$ and goal, $\mathrm{F}=30.29 ;$ all $\mathrm{dfs}=1 / 63 ;$ all $\mathrm{ps}<.001)$.

The results of Duncan's range tests indicated that Group PP showed a PRE relative to Group $R C$ in the goal section by the second block of trials $(p<.05$, by Block $3, p<.01$ ), in the run section only by the third block of trials $(p<.05)$, and not at all in the start section. Furthermore, Group PP ran significantly more slowly than Group RP on all trial blocks in the start and run sections, but differed significantly from Group RP only on the first block of trials in the goal section. These critical individual comparisons provide additional statistical support for the generalization that, as extinction progressed and as the goal section was approached, type of acquisition training became increasingly less relevant to performance, while schedule of reward became increasingly more relevant to performance.

\section{DISCUSSION}

In the absence of any overt instrumental acquisition training, DPs produced a PRE. In the present experiment influence of type of acquisition training declined and the influence of schedule of reward increased both as extinction training progressed and as the goal section was approached. As a result of these opposing trends, Group PP showed a PRE almost as large as that of Group RP by the third block of extinction trials in the goal section.

The frustration (Amsel, 1958) and sequential (Capaldi, 1966) hypotheses explain the PRE, generally speaking, by assuming that internal stimuli ultimately related to reward and nonreward are conditioned to the instrumental reaction. For hypotheses of this type, then, the PRE shown by Group PP implies both that internal stimuli are occasioned on DP trials and that instrumental responding occurs on DP trials. The instrumental response assumption supports the view of Hurwitz (1955), who assumed that on DP trials terminal portions of the full instrumental response occur. Since in this investigation the DPs were not accompanied by normal instrumental trials, the possibility that the instrumental components were contributed from sources other than the DPs themselves seems to have been effectively excluded. The PRE in Group PP also suggests that various anticipatory response views, of which that of Moltz (1957) is representative, need to be supplemented by an instrumental-response conception such as Hurwitz's. According to Moltz, for example, while the $r_{g}$ reaction occurs on DP trials, the instrumental reaction does not. Many studies, for example those employing rewarded DPs prior to instrumental training (e.g., Stein, 1957) or nonrewarded DPs following instrumental training, so-called latent extinction (e.g., Dyal, 1962), are based on some variety of the Moltz view, i.e.. that by employing DPs one can evaluate the contribution of specific reward conditions (classical conditioning) to performance in the absence of instrumental responding. However, as we have seen, the DP-produced PRE suggests the involvement not only of the general kind of mechanism assumed by Moltz but of instrumental responding as well (Hurwitz, 1955). The present results suggest, then, that one of the major historical rationales for employing DPs, i.e., in order to separate the effects of reward conditions (expectancy, $r_{g}$, etc.) from instrumental responding may not be valid. Apparently it is quite difficult to eliminate instrumental responding. Until better information is available concerning the conditions under which instrumental responding may or may not be eliminated in particular situations, it may be appropriate to remain open to the possibility that instrumental responding may have occurred and that its effects are almost totally unknown.

The following observations possibly provide a hint as to the source of the instrumental reactions occurring on DP trials. It was agreed by both Es that Ss squirmed forward in E's hand, vigorously so, as they were being placed, and hunched forward as they ate the pellets, perhaps to gain a better eating position. On nonrewarded DP trials, Ss soon turned away from the food cup in favor of sniffing, etc., about the goalbox. It may be assumed that in the DP situation $S$ learns an instrumental approach reaction. Label this reaction the $R_{1}$ reaction, in contrast to the full instrumental approach reaction $\left(R_{2}\right)$. In order to explain the gradient over alley sections obtained here it may be assumed that stimuli such as $s_{f}$ (Amsel, 1958) or $\mathrm{S}^{\mathrm{N}}$ (Capaldi, 1966) tend most strongly to evoke the reaction to which they were directly conditioned, i.e., the $\mathrm{R}_{1}$ reaction. Presumably as $S$ moves from start to goal the various components of the $R_{2}$ chain become increasingly similar to the DP or $R_{1}$ reaction. Thus, it follows that the PRE in Group PP would be larger as $S$ approached the goal section. Ross (1964), 
in a somewhat different experimental context, has already suggested this "response similarity" hypothesis. While Ross applied the hypothesis between reactions, c.g., jump $\left(R_{1}\right)$ to run $\left(R_{2}\right)$, it can be applied equally well, as here, to the individual components comprising a so-called single reaction.

The present experiment and that of Witon (1967) produced a DP PRE, while the investigations of Trapold \& Doren (1966) and Trapold \& Holden (1966) did not. These discrepant results may be attributed to the magnitudes of reward employed in the various investigations. The present investigation employed a relatively large food reward (12 pellets) and Wilton (1967) employed a relatively large sucrose reward (30-sec access to a $50 \%$ solution), while Trapold and Doren employed only a 3-pellet reward $(.045 \mathrm{~g})$ and Trapold and Holden employed an 8-pellet reward. Since the PRE is greater following a larger magnitude of reward in the normal instrumental situation (e.g., Wagner, 1961), it might be expected that it would also be larger following a larger magnitude of DP reward. Interestingly, there was a greater tendency toward a DP-produced PRE in the Trapold and Holden study ( 8 pellets) than in the Trapold and Doren study (3 pellets).

REFERENCES

AMSEL, A. The role of frustrative nonreward in noncontinuous reward situations.
Psychological Bulletin, 1958. 55, 102-119.

CAPALDI, 1:. J. Partial reinforcement: An hypothesis of sequential effects. Psychological Review, 1966, 73, 459-477.

DYAL, J. A. Latent extinction as a function of number and duration of preextinction exposures. Journal of Experimental Psychology, 1962, 63, 98-104.

HURWITZ, H. M. B. Response elimination without performance. Quarterly Joumal of Experimental Psychology, 1955, 7, 1-7.

MOLTZ, H. Latent extinction and the fractional anticipatory response mechanism. Psychological Review, 1957, 64, 229-241.

ROSS, R. R. Positive and negative partial-reinforcement extinction effects carried through continuous reinforcement, changed motivation, and changed response. Joumal of Experimental Psychology, 1964, 68, 492-502.

STEIN, L. The classical conditioning of the consummatory response as a determinant of instrumental performance. Journal of Comparative \& Physiological Psychology, $1957,50,269-278$.

TRAPOLD, M. A., \& DOREN, D. G. Effect of noncontingent partial reinforcement on the resistance to extinction of a runway response. Joumal of Comparative \& Physiological Psychology, 1966, 71, 429-4.

TRAPOLD, M. A., \& HOLDEN, D. Noncontingent partial reinforcement of running: A replication. Psychonomic Science, $1966,5,449-450$.

WAGNER, A. R. Effect of amount and percentage of reinforcement and number of acquisition trials on conditioning and extinction. Journal of Experimental Psychology, 1961, 62, 234-242.

WILTON, R. Extinction of a runway response following runway or goalbox partial reinforcement. Quarterly Journal of Experimental Psychology, 1967, 19, 162-169.

\title{
Prediction and control of schedule-induced drink durations
}

\author{
J. D. KEEHN and V. A. COLOTLA \\ York University and Addiction Research Foundation, Toronto, Ont., Canada
}

Six white rats were reinforced continuously for one, three, six, or nine successive barpresses at the end of fixed intervals of $1 \mathrm{~min}$ [schedule mix FI 1 CRF ( $n)$ ]. Schedule-induced drinking became controlled by the onset of the FI in that drinking rarely occurred when food was available on CRF. Drink durations were predictable but were not related to "meal size" over the range of one through nine 45 -mg Noyes pellets.

When rats are fed pellets of food intermittently, they typically engage in a bout of drinking shortly after each pellet is delivered (Falk, 1961). These postpellet drinks are of relatively constant duration (Keehn \& Colotla, 1970), in contrast to the apparently random durations of drinks that occur when feeding is not constrained. The present paper is concerned with the were much longer than those following one 45-mg pellet (Falk, 1967, Fig. 4). Falk's data suggest that increasing meal size destroys the predictability of drink burst durations, but this may have been because his animals received insufficient exposure to the larger meal condition.

Our procedure differed from Falk's in that we used a mixed schedule of reinforcement as a way of controlling meal size; that is, we programmed continuous reinforcement (CRF) for $n$ responses at the end of fixed intervals of $1 \mathrm{~min}$ (FI $1 \mathrm{~min}$ ). SUBJECTS

Six mature white rats that had previously taken part in an experiment on schedule-induced polydipsia were used. They had been rested for 2 weeks prior to the present experiment but maintained at $80 \%$ of their free-feeding weights. They were kept at the $80 \%$ weight level throughout the present experiment. They were housed in individual cages in which tap water was continuously available.

\section{APPARATUS}

A standard Grason-Stadler two-bar rat chamber, Type E3125 B, was employed. The left-hand bar was removed and its opening covered with a metal plate mounted flush with the wall. A weight of $20 \mathrm{~g}$ on the remaining bar activated relay programming and recording apparatus. A plastic water bottle was attached to the chamber door so that the glass outlet tube from the bottle protruded $6 \mathrm{~mm}$ into the chamber through a hole $90 \mathrm{~mm}$ from the wall containing the bar and food magazine and $25 \mathrm{~mm}$ above floor level. Licks at this tube were recorded on a Gerbrands cumulative recorder via a Grason-Stadler drinkometer. The experimental chamber was housed in a ventilated chest supplied with a viewing window (Grason-Stadler Model E3125-3).

\section{PROCEDURE}

Because the animals were experienced, no pretraining was necessary. Experimental sessions were $2 \mathrm{~h}$ long, every other day. For the first three to five of these sessions,

Table 1

Number of Sessions in Which Each Animal was Run Under Each Condition

\begin{tabular}{lcccccc}
\hline & \multicolumn{7}{c}{ Subject } \\
\cline { 2 - 7 } tion & C1 & E1 & C2 & E2 & C3 & E3 \\
\hline CRF & 5 & 5 & 3 & 4 & $3 *$ & 4 \\
FI 1 & 4 & 4 & 4 & 3 & 2 & 2 \\
CRF 9 & 4 & & & & & \\
FI 1 & 4 & 4 & 4 & 4 & 4 & 4 \\
CRF 6 & 4 & & & & & \\
FI 1 & 4 & 4 & 3 & 4 & 4 & 4 \\
CRF 3 & 4 & & & & 10 & 10 \\
FI 1 & 10 & 10 & 9 & 11 & 10
\end{tabular}

* C3 was run for two sessions in FI 1 after the CRF sessions and before the FI I CRF 9 condition. 